\title{
ToU Tariff Effect on Domestic Electricity Patterns- Australian Case Study
}

\author{
Glen Thomas Currie ${ }^{1}$ (D)
}

Received: 17 November 2019 / Accepted: 27 March 2020 / Published online: 4 May 2020

(C) Springer Nature Singapore Pte Ltd. 2020

\begin{abstract}
This article shows an evaluation of a ToU network tariff test on Australian domestic electricity customers. The test was with 444 domestic electricity customers in Tasmania, Australia. This Australian case has international implications for energy policy and regulation. Australia has the world's highest domestic PV (photovoltaic system) adoption and combining this with high airconditioning and water heating load leads to high diurnal variation and an emerging issue globally. Related issues include overvoltage. Thermal overload, frequency instability and voltage instability.

The method was a statistical analysis of the energy use patterns using k-means clustering, and then stepwise regression to find drivers of energy reduction behaviour. There were also tests on the effect of weather and seasonal effect.

The conclusions are that there was strong response from $4 \%$ of customers, and moderate response from $15 \%$. There was a stronger response in households that were drawing more electricity and were wealthier than the average households.
\end{abstract}

Keywords Electricity networks $\cdot$ Duck-curve $\cdot$ Low voltage grids $\cdot$ Network tariff

\section{Introduction and Motivation}

Electricity systems around the world are facing increasing diurnal variation. Major causes are solar PV and air-conditioning. This has been characterised as the "duck-curve" [1]. Australia has the world's highest domestic PV (photovoltaic system) adoption and combined with high air-conditioning and electric water-heating load, leads to particularly high diurnal variation. This variation makes supply more difficult and reduces asset return due to low asset utilisation. Related issues include, overvoltage, thermal overload, frequency instability and voltage instability. ToU tariffs are one solution for these problems.

Time of Use (ToU) pricing can shift some loads to daily off-peak periods [2]. For these benefits there needs to be widespread take-up and changes in customer houses. This paper measures both the take-up of ToU and related energy actions in a population in Tasmania, Australia. The literature suggests $5-10 \%$ of customers will "opt-in" and sustain effort to modify

Glen Thomas Currie

glen.currie@unimelb.edu.au

1 School of Engineering, The University of Melbourne, Melbourne, Australia their energy use [3]. Stenner et al. also argue that hardware change is a more potent tool for sustained results. This is because the consumers who change their hardware to implement advanced control can set-and-forget.

The Australian electricity system is in separate generation, distribution, and retail as shown in Fig. 1.

The arrows in Fig. 1 show the flow of power and control that suggests a key role for the national government upstream and influence of state governments downstream in the electricity system.

\section{Methodology}

Customer data were collected in the EmpoweringYou trial between January 2016 and January 2018 [4]. Responsiveness to a January 2017 tariff change was analysed.

Customers shared electricity use data for two years, and a tariff change occurred in the middle of that period. The method was to cluster customers using k-means clustering and then consider the drivers of these different behaviours using stepwise regression. $\mathrm{k}$-means is a vector method where a target of " $\mathrm{n}$ " observations is clustered in " $\mathrm{k}$ " clusters. Each customer in this trial was given to a cluster using their mean use of electricity. The calculation of the k-means groups requires a 
Fig. 1 Key stakeholders in the Australian electricity system

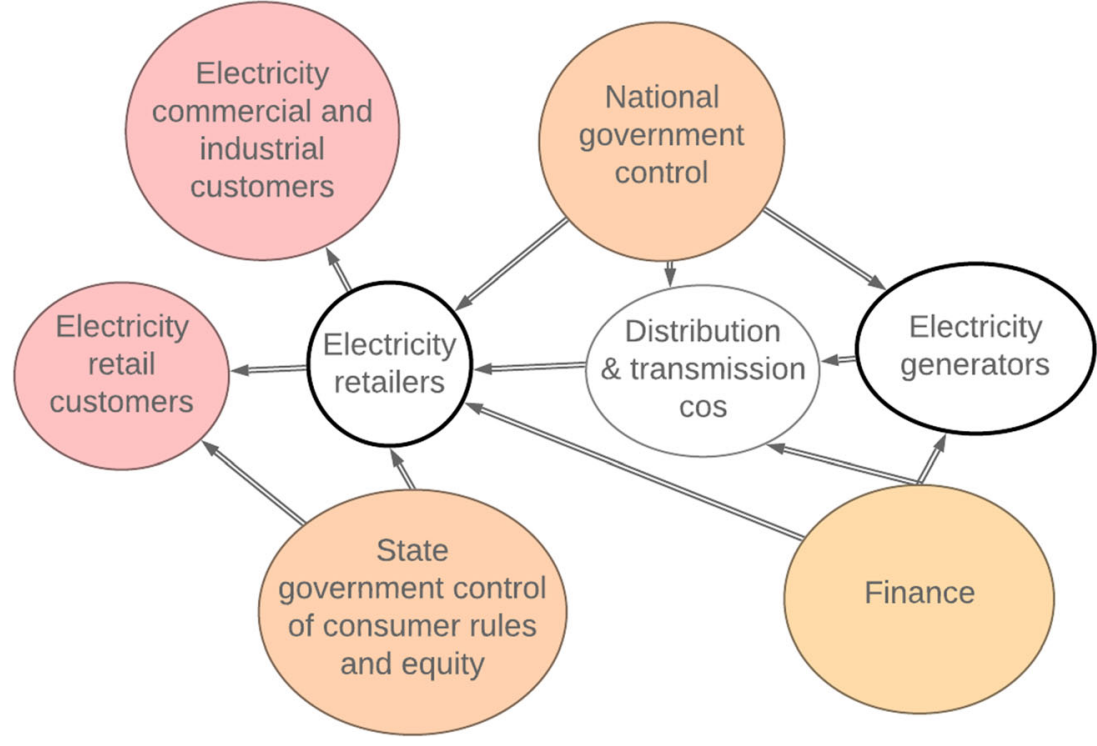

choice of the target " $k$ ". The software used was Microsoft Excel.

\section{Methodology}

This research is to measure behaviour in a specific Tasmanian population with the goal of choosing pricing settings to help manage the electricity system.

The testing in this research is for a minor tariff change and is not a fully dynamic pricing system. Therefore the EmpoweringYou trial is expected to have low elasticity of electricity demand as there is a low price change [5].

\section{Method}

The datasets follow.

- Weather in 15-min increments for the 2-year period.

- Interval data and survey data for 600 households in the EmpoweringYou trial.

- Consumption data for 8343 customers in the Brighton Municipality who were not in the EmpoweringYou trial.

The steps of analysis follow.

- Data cleaning: gave an outcome of 444 customer datasets.

- Data manipulation: merged data from multiple surveys and the half hourly weather data- 22 Million records.

- Data coding: coding of survey data to allow regression to work. Questions were sometimes combined to a single scale.

- Summarising interval data into an average for each half hour: a change of peak for each month, season, annual, and by peak/off-peak.
- Stepwise regression of year on year change.

- Stepwise regression of seasonal peaks.

- Autocorrelation of weather to $\mathrm{kW}$ relationship.

- k-means clustering of the load patterns.

- Identification of 72 customers (16\% of trial) that reduced in winter.

- Identification of 18 customers (4\%) that reduced in 3 or 4 seasons and called Strong Responders.

- Feeder analysis to check the impact by feeder.

- k-means clustering to find common demand profiles by feeder.

- Modelling profiles to feeder to determine feeder level impact of ToU tariff.

Fig. 2 is another customer data set but illustrates how different customers use electricity in differently and shows how the clustering is driven.

\section{The Customers Studied Were in the EmpoweringYou Trial}

An Australian company TasNetworks commissioned a ToU tariff trial called EmpoweringYou which ran from 2016 to 2018. This trial included installation of interval meters on 600 houses, and measured household structure and preferences. There was a full year of measurement, then a new ToU tariff and a further year of measurement.

The customers in this trial were in and around the Brighton Municipality of Hobart, Tasmania, Australia [4]. The characterisation of these customers was: $20 \%$ with solar panels, $48 \%$ tertiary educated, $57 \%$ home most of the day, an average household income of $\$ \mathrm{~A} 47,365$, consumed $9 \mathrm{kWh}$ on average, $26 \%$ retired, $36 \%$ employed and had an average of 2.7 people per household. 


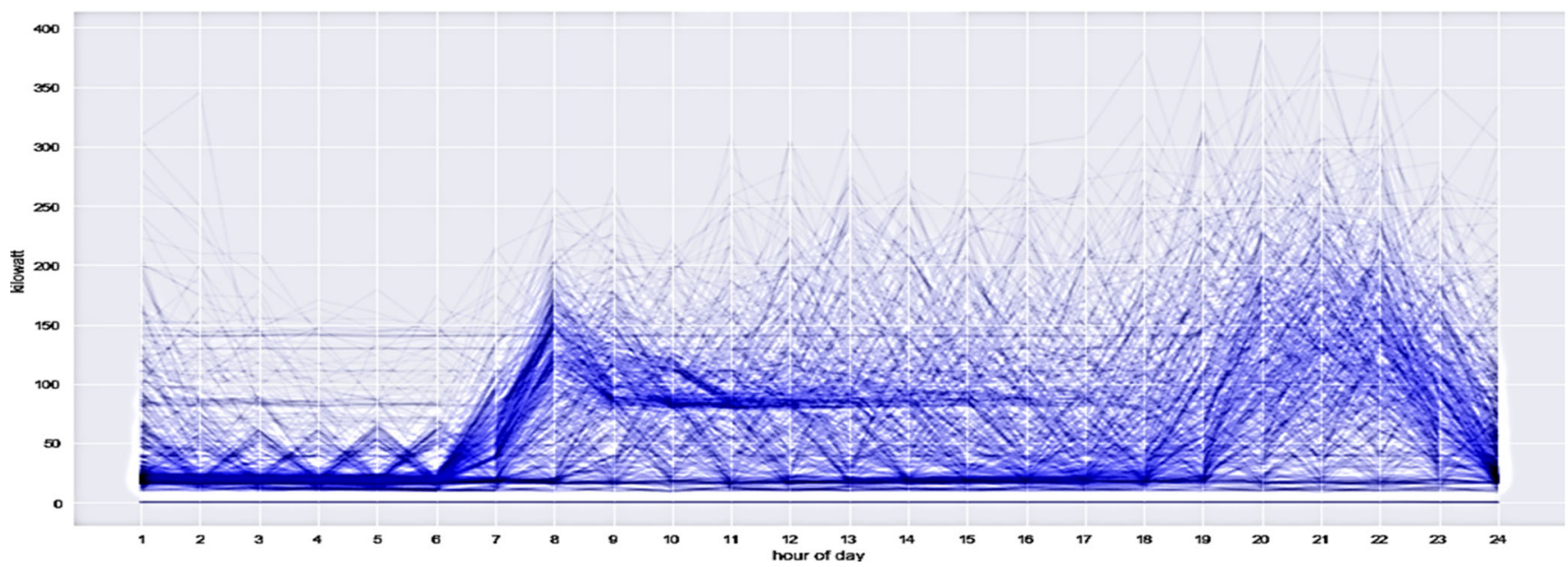

Fig. 2. k-means cluster calculation showing the concentrations of customer loads

The new network tariff evaluated in the EmpoweringYou trial was a demand-based time-of-use tariff with daily service change and two daily demand charges. The tariff included peak and off peak but had no shoulder price and no seasonal pricing. The new tariff charged for the top four monthly highest peak period demands between 7 a.m.-10 a.m. and 4 p.m.-9 p.m.

Maximum demand of each customer set their off-peak price. There was a reward of an $83.6 \%$ reduction in demand charge for customers who reduced their peak use or moved use away from peak periods. This decreased their network price from $\$$ A $0.30 / \mathrm{kW}$ to $\$ \mathrm{~A} 0.05 / \mathrm{kW}[4]$.

\section{Results}

\section{Was there a Seasonal Variation in Responsiveness to ToU?}

Overall, the reduction was just over $2.5 \%$ in peak periods and just under $2.5 \%$ in off peak periods. This shows in Fig. 3 where the seasonal change (year on year) of the trial participants shows in orange, and the control group in blue.
The change in consumption for the trial participants $(n=$ 444) was significant. The other customers in the Brighton Municipality, who are the control in this comparison increased their Summer and Autumn usage on average.

\section{Were there Certain Customer Groups Who Responded Stronger than Others?}

Eighteen customers reduced their electricity 3 or 4 seasons of the section year and these are Strong Responders. This was $4.1 \%$ of the people in the trial. This group of people reduced their peak period load $15 \%$ as shown in Fig. 4.

This group of Strong Responders also made a significant reduction in their peak $\mathrm{kW}$ on the network peak days as shown in Fig. 5. Peak kW on peak days is a significant measure, as this determines the quantity of network assets required to supply that customer.

Apart from that group of Strong Responders, another group of 72 customers reduced their demand in the winter. This was $10 \%$ reduction in peak $\mathrm{kW}$ and $20 \%$ reduction in consumption during peak periods. Their reduction was throughout the day, but their biggest reduction was in the morning peak.
Fig. 3 Consumption Changes between the trial participants and the non-participants [4]

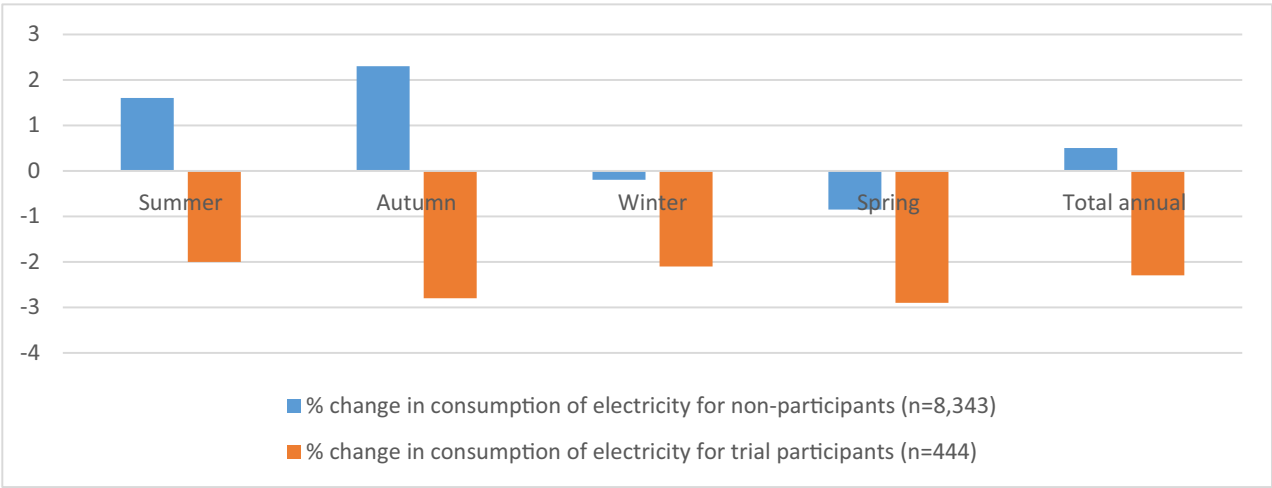


Fig. 4 Change in demand from previous year for Strong Responders Group [4]

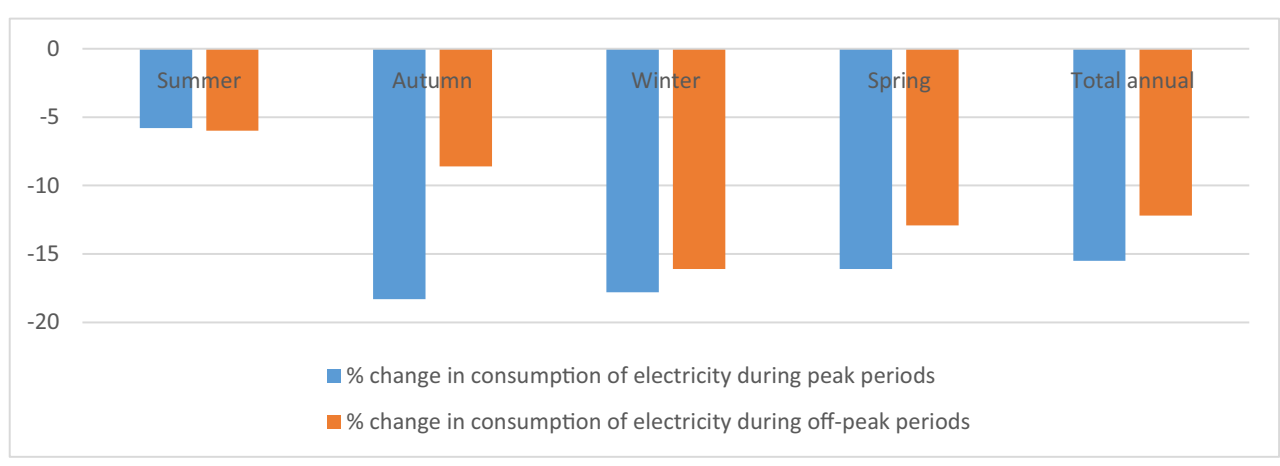

\section{What Was the Pattern of Electricity Use on the Two Peak Days?}

The $\mathrm{kW}$ utilisation of the Strong Responders on the two network peak days (3 June 2017, and 28 June 2018) show in Fig. 6. This is the average pattern of use for these 18 customers over the two peak network days. They are both winter days which is when the Tasmanian electricity peak occurs (unlike other parts of Australia which have a summer peak).

Fig. 6 shows the change on the peak days for the Strong Responder group was throughout the day except for 1 p.m. to 3 p.m. and then after 10 p.m. Strong Responders made clear reductions during the peaks at 8 a.m. and 9 p.m.

\section{Were Usage Changes Driven by the Response to a Price Signal or another Factor?}

Alternate influences on the household electricity use include weather, changes in the household, and the trial-effect.

- Weather has negligible effect during winter due to the constant heating load with most heaters running at or near their maximum load. There is a response to weather in the other seasons though this shows a lag that is worth further research.
- Changes in the household that were statistically significant were buying an electric hot water system or new heat pump.

- The trial-effect is behaviour change due to the trial, not in response to the tariff change. There was a trial-effect detected, but there was no measure set up to allow it to be quantified.

These influences from weather, the changes in the household and trial-effect were considered during analysis but were considered minor effects.

\section{What Are the Network Implications?}

The network is where most capital lies, so any implications for the network are important. Therefore, the question is whether the cost-reflective tariffs could result in a peak demand reduction that requires less network assets.

Fig. 7 shows the theoretical outcome if all trial customers were on one feeder. This suggests there is little opportunity to reduce peaks at the feeder and substation level because there was not a significant decrease in either the morning peak or the evening peak.

Fig. 7 shows data from TasNetworks Feeder Number 48185 where $78 \%$ of the load comes from residential customers. The "Scenario of Feeder Profile" assumes all customers respond in the same way as customers did in the EmpoweringYou trial.

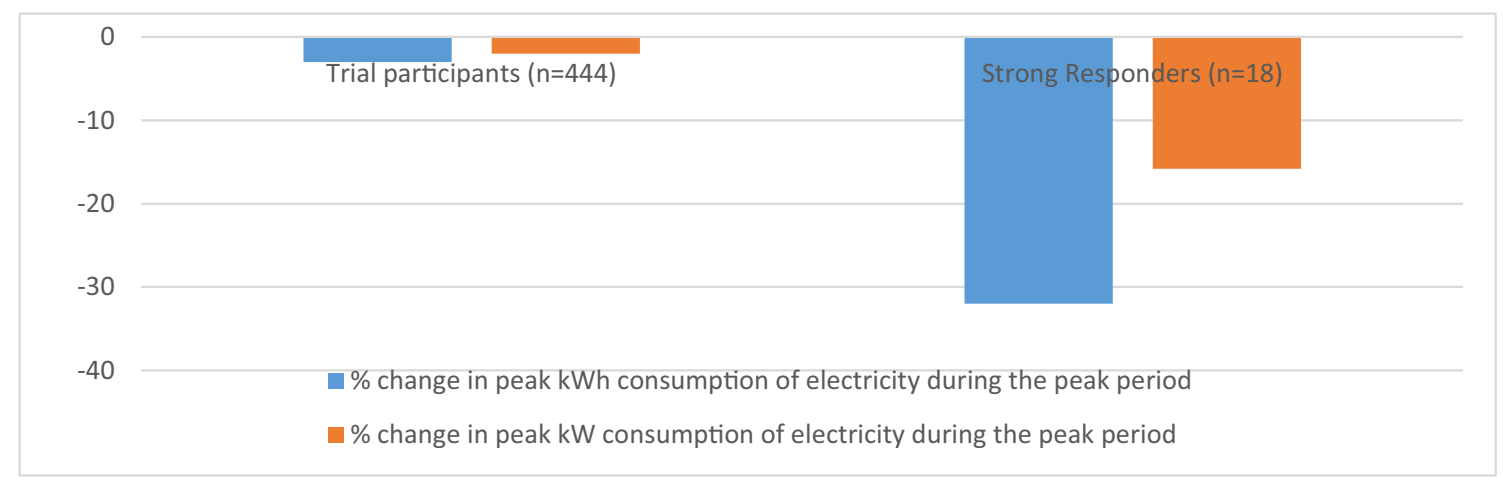

Fig. 5 Change in kWh Peak and kW Peak consumption change [4] 
Fig. 6 Average $\mathrm{kW}$ load for homes in the Strong Responder Group for two peak network days [4]
Strong Responders on two peak days

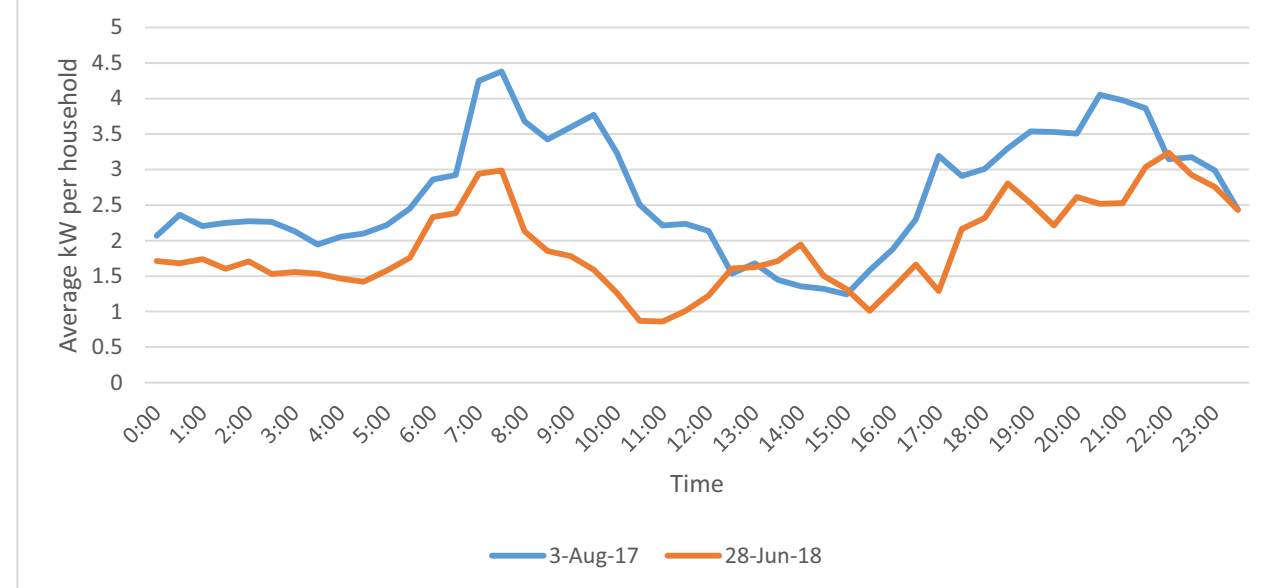

\section{Discussion}

To overcome issues from the "duck-curve" distribution businesses can install expensive equipment such as onload tap changers (OLTC), mechanical voltage regulators, power electronic voltage regulators, STATCOMS, transformer upgrades and line drop compensators (LDC's) [7]. An alternative solution lies with nudging customers to alter their load profile which could reduce their negative impact on the grid.

\section{Hardware Upgrades and Smart Meters}

Hardware changes might include new air-conditioning hardware, dishwashers, washing machines, and fridges. New hardware often includes control algorithms that help the grid. For example "Consort" uses game theory to equitably allocate charging for Electric Vehicles [8]. There are many similar companies [9] and theoretical concepts [10].

The current tariff setting process in Australia is a barrier to setting up data systems to set prices, and the speed of innovation in regulation is slow (minimum of 18 months for a minor change). Rather than directing tariff rules in a centralised system, the speed of innovation would be higher if distribution businesses were enabled to introduce new pricing to best optimise their assets. This could be achieved by incentivising distribution companies to reduce prices for unconstrained assets and focusing their pricing innovation on their constrained assets. Other market incentives could include encouraging home storage, installation of more efficient hardware, load deferral, and home insulation style innovations.

Australian distribution companies have reduced peak load by up to $30 \%$ with control of air-conditioning in South Australia and NSW [11] where discounts and cash payments are made in exchange for allowing air-conditioning compressor control. Australian distribution companies have reduced peak load by up to $30 \%$ with control of air-conditioning in South Australia and NSW [11] where discounts and cash payments are made in exchange for allowing air-conditioning compressor control. There also is increasing interest in the control of residential storage ([12].).
Fig. 7 The theoretical effect of the ToU change on network peaks at the feeder level [4]

\section{Feeder 48185 showing the scenario of the trial outcome on the whole feeder}

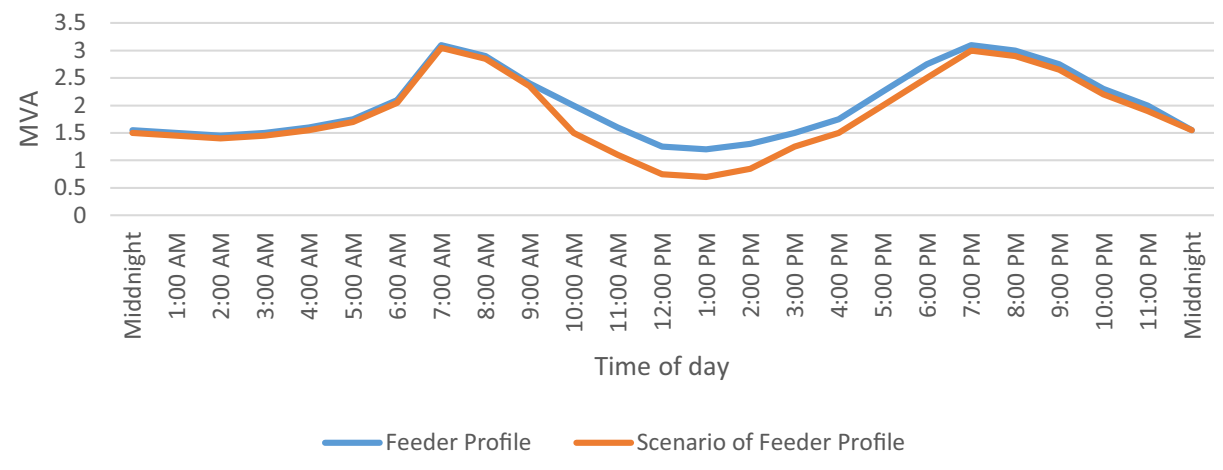




\section{Control of Loads}

Research suggests the most effective action is through control. Control options include, connect and disconnect, adjustable peak generation, adjustable power factor, Volt-VAR mode to adjust reactive power, frequency ride-through and voltage ride-through to set voltage parameters governing inverter connection shutoff [13].

Control options offer a capability to manage voltage by curtailment or the redirection to storage. In Tasmania, electric hot water would be widely available for storage. Customers will accept controls on their household if they are rewarded for this [14].

Control of loads and storage can offer the strongest tool to counter the duck-curve. One advantage of control is that it can be very targeted to the location of network constraint (by comparison it is difficult to target ToU). Control can be on both a temporal and a spatial level on the constrained network. The annual peak in other parts of Australia is a summer peak, but the Tasmanian annual peak is winter. Their lowest monthly average temperature is $11.8 \mathrm{C}$, and the highest monthly average summer temperature $25.9 \mathrm{C}$ as shown in Table 1.

Internationally, the need for improved control of loads on low voltage systems is recognised [15] and methods include distributed energy resource management systems for improved distribution grid control [16].

\section{Behavioural Economics}

Behavioural economics can help us understand how customers will respond. The literature on Australian electricity customers includes exploration of distrust in direct load control [17], household energy use [18], and response to cost reflective electricity pricing [3]. This literature is founded on seminal work on prediction [19], decision making [20] and dynamic pricing [21].

Behavioural Economists consider that small decisions use a different decision process than large decisions. Vis a viz. customers approach big buying decisions with high caution and are more effected by the customer peer group and not the technical aspects.

Facilitation of customer response to ToU pricing, will get higher response than increasing customer motivation [22]. This may have importance in designing communications to clients. An example of this dynamic: Australian customers are increasingly aware of their role in sustainable energy practices but their behaviour does not reflect this awareness [18].

\section{Choosing a Suitable Tariff}

There is a rich literature on network tariff design. Of particular note Faruqui and Lessem [23] and Schweppe, Caramanis, and Tabors [24].

A review of tariff options for Tasmanians was completed in 2018 by the not-for-profit Sustainable Living Tasmania [25]. Further to this, a recent review of the ToU offer in NSW suggests the ToU option is not working in NSW [26] and other researchers in the same team suggest an alternate tariff structure [27].

Dynamic pricing [28] relies on smart meters being installed, which is not the case in Tasmania. Dynamic pricing may become a useful tool but consumer preferences should be considered [21].

There is a political sensitivity to ToU pricing because behavioural economics shows us that customers are most comfortable with the status quo, even when the deferred benefit is far higher than their perceived benefit by sticking with the status quo [3]. Therefore, tariff design is a social-technical challenge. There is political concern that ToU pricing disadvantages people through their poor access to capital, or difficulty in evaluating their choices. Economists would like to see locational pricing for example, but this is politically unacceptable, due to a social contract between rural and urban Australians to subsidise services to rural areas.

The other key constraint on tariff choice is regulation which is starting to innovate in Australia. A demand management trial has recently been run by the Australian Government [29]. This trial saw retailers and other participants bidding on Demand Response. For example, one retailer sent three text messages to their retail consumers that offered a set reduction in load for \$A 10 for each successful reduction. In another example the distribution companies responded by setting their voltage to $209 \mathrm{~V}$ for $2 \mathrm{~h}$ (the nominal voltage in that case was $230 \mathrm{~V}$ ).

Of all the system interventions, the highest return is likely to the establishment of temporal network pricing, but it would primarily be suited to reward the owners of batteries and electric vehicles. Another ancillary benefit of the higher data flows

Table 1 Monthly temperature averages in Hobart, Tasmania

\begin{tabular}{|c|c|c|c|c|c|c|c|c|c|c|c|c|c|}
\hline Statistic & Jan & Feb & Mar & Apr & May & Jun & Jul & Aug & Sep & Oct & Nov & Dec & Annual \\
\hline Mean & 21.7 & 21.7 & 20.2 & 17.4 & 14.5 & 12.0 & 11.8 & 13.1 & 15.1 & 17.0 & 18.7 & 20.4 & 17.0 \\
\hline Lowest & 19.1 & 18.7 & 17.7 & 15.0 & 12.0 & 9.4 & 10.2 & 10.3 & 12.0 & 13.6 & 15.3 & 17.4 & 15.7 \\
\hline Highest & 25.9 & 25.2 & 22.9 & 20.4 & 17.3 & 14.1 & 13.9 & 15.7 & 17.9 & 20.0 & 22.4 & 24.0 & 18.5 \\
\hline
\end{tabular}


that dynamic pricing would being include better decisions on purchase and use of technology such as air-conditioning, and PV. Dynamic pricing is at least a decade away in Australia, but planning should start now.

\section{Thermostats}

Resetting thermostats on air-conditioning may offer a way to respond to the duck-curve. The saturation effect has found that once all the air-conditioning is at maximum power, there is no electricity response to temperature change in summer [30]. This showed for the winter in the EmpoweringYou data.

People will still want to run their air-conditioning and will be unresponsive to changing their thermostats. There may be a motivated group of customers willing to alter their electric hot water and air-conditioning but the take-up is unlikely to have a significant effect on the duck-curve and may build political backlash as customers generally believe it must remain their personal prerogative to set their thermostat to a certain temperature.

\section{Conclusion}

This research analyses the responsiveness of 444 domestic electricity customers to a change to their tariff. These customers provided two years of interval electricity data with a price change in the middle of the period. TasNetworks sent these customers ideas on reducing their electricity load. This led to a strong response from $4 \%$ of customers, and moderate response from $15 \%$. There was a stronger response in households that were drawing more electricity and were wealthier than the average households. Their most common action was to replace their heat pump (air-conditioning unit). The result that can be generalised is that customers who use electricity and who are wealthier can respond to a ToU tariff.

The use of k-means clustering proved a robust segmentation method using the temporal load data. The other method of stepwise regression allowed an exploration of key drivers of customer behaviour.

Weather had negligible effect during winter when the heating load is constantly working to counter the cold. There is a response to weather in the other seasons though this shows a lag that is worth further research.

This research offers a starting point for pricing decisions and may offer value to planning and strategy decisions.

\section{References}

1. Denholm P, O'Connell M, Brinkman G, Jorgenson J (2015) Overgeneration from solar energy in California: a field guide to the duck chart. National Renewable Energy Laboratory Golden, $\mathrm{CO}$

2. Wijaya, T. K., Vasirani, M., Villumsen, J. C., \& Aberer, K. (2015, 25 Nov. 2015). An economic analysis of pervasive, incentive-based demand response. Paper presented at the 2015 Ieee international conference on smart grid communications (Smartgridcomm)

3. Stenner, K., Frederiks, E., Hobman, E. V., \& Meikle, S. (2015). Australian consumers' likely response to cost-reflective electricity pricing. In CSIRO

4. TasNetworks. (2019). Empowering You Trial Summary Report. Retrieved from https://www.tasnetworks.com.au/config/ getattachment/15dd6c15-6386-42da-b73c-f7 12f598de2c/ empowering-you-final-report-summary.pdf

5. Adom PK (2017) The long-run price sensitivity dynamics of industrial and residential electricity demand: the impact of deregulating electricity prices. Energy Econ 62:43-60

6. Viola, L. G. (2018). Clustering electricity usage profiles with Kmeans. Retrieved from https://towardsdatascience.com/clusteringelectricity-profiles-with-k-means-42d6d0644d00

7. Alexander D., Wyndham J., James G., \& L., M. (2017). Networks renewed: technical analysis. Retrieved from Sydney, Australia: https://www.uts.edu.au/sites/default/files/NetworksRenewed TechnicalAnalysis.pdf

8. Consort. (2019). Company Website. Retrieved from http://www. consort-statement.org/about-consort

9. Ganu T, Seetharam DP, Arya V, Hazra J, Sinha D, Kunnath R et al (2013) Nplug: an autonomous peak load controller. IEEE Journal on Selected Areas in Communications 31(7):1205-1218

10. de Hoog J, Alpcan T, Brazil M, Thomas DA, Mareels I (2016) A market mechanism for electric vehicle charging under network constraints. IEEE Transactions on Smart Grid, IEEE, New York (United States) 7(2):827-836

11. Ausgrid. (2018). Ausgrid Regulatory Response for 2019-24. Retrieved from http://energyconsumersaustralia.com.au/wpcontent/uploads/Ausgrid-Regulatory-proposal-2019-24Submission-to-the-AER-Issues-Paper.pdf

12. Procopiou AT, Petrou K, Ochoa LF, Langstaff T, Theunissen J (2018) Adaptive decentralized control of residential storage in PV-rich MV-LV networks. IEEE Transactions on Power Systems, IEEE New York (United States)

13. Reiter E, Ardani K, Margolis R, Edge R (2015) Industry perspectives on advanced inverters for US solar photovoltaic systems, Grid Benefits, Deployment Challenges, and Emerging Solutions (NREL/TP-7A40-65063). Retrieved from Golden, CO (United States) https://www.nrel.gov/docs/fy15osti/65063.pdf

14. Ochoa LN, Pilo F, Keane A, Cuffe P, Pisano G (2016) Embracing an adaptable, flexible posture: ensuring that future European distribution networks are ready for more active roles. IEEE Power and Energy Magazine, IEEE New York (United States) 14(5):16-28. https://doi.org/10.1109/MPE.2016.2579478

15. Guangya Y, Marra F, Juamperez M, Kjaer SB, Hashemi S, Østergaard J et al (2015) Voltage rise mitigation for solar PV integration at LV grids. Journal of Modern Power Systems and Clean Energy, Springer, New York (United States) 3(3):411-421

16. Strezoski, L., Stefani, I., \& Brbaklic, B. (2019). Active Management of Distribution Systems with High Penetration of Distributed Energy Resources. Paper presented at the IEEE EUROCON 2019-18th international conference on smart technologies

17. Stenner K, Frederiks ER, Hobman EV, Cook S (2017) Willingness to participate in direct load control: the role of consumer distrust. Appl Energy 189:76-88

18. Frederiks ER, Stenner K, Hobman EV (2015) Household energy use: applying behavioural economics to understand consumer decision-making and behaviour. Renew Sust Energ Rev 41:13851394 
19. Kahneman D, Tversky A (1973) On the psychology of prediction. Psychol Rev 80(4):237

20. Chatterjee, K., \& Samuelson, W. (n.d.) Game Theory and Business Applications

21. Dütschke E, Paetz A-G (2013) Dynamic electricity pricing — which programs do consumers prefer? Energy Policy 59:226-234

22. Alford J (2002) Why do public-sector clients coproduce?: toward a contingency theory. Administration \& Society 34(1):32-56. https:// doi.org/10.1177/0095399702034001004

23. Faruqui, A., \& Lessem, N. (2012). Managing the benefits and costs of dynamic pricing in Australia. Retrieved from http://citeseerx.ist. psu.edu/viewdoc/download?doi=10.1.1.640.999\&rep= rep1\&type $=$ pdf

24. Schweppe FC, Caramanis MC, Tabors RD (1985) Evaluation of spot price based electricity rates. IEEE Transactions on Power Apparatus and Systems 7:1644-1655

25. Tasmania, S. L. (2018). Which tariff should I use? Retrieved from https://www.slt.org.au/tariffs
26. Young, S., Bruce, A., \& Macgill, I. (2019). Potential impacts of residential PV and battery storage on Australia's electricity networks under different tariffs (Vol. 128)

27. Passey R, Haghdadi N, Bruce A, MacGill I (2017) Designing more cost reflective electricity network tariffs with demand charges. Energy Policy, Elsevier. Amsterdam (Netherlands) 109:642-649

28. Faruqui A, Hledik R, Sergici S (2009) Piloting the smart grid. Electr J 22(7):55-69. https://doi.org/10.1016/j.tej.2009.06.012

29. AEMO. (2017). AEMO AND ARENA DEMAND RESPONSE TRIAL TO PROVIDE 200 MEGAWATTS OF EMERGENCY RESERVES FOR EXTREME PEAKS. Retrieved from https:// www.aemo.com.au/Media-Centre/AEMO-and-ARENA-demandresponse-trial-to-provide-200MW-of-emergency-reserves-forextreme-peaks

30. Graham PW, Hayward J, Foster J, Story O, Havas L (2018) GenCost, Australia

Publisher's Note Springer Nature remains neutral with regard to jurisdictional claims in published maps and institutional affiliations. 